\title{
JUVENTUDES E MEDIDA SOCIOEDUCATIVA: O OLHAR DOS AGENTES PEDAGÓGICOS SOBRE AS PRÁTICAS DE LAZER
}

\author{
Dayane Ferraz Lacerda Trentin \\ Universidade Estadual de Campinas, Campinas, São Paulo, Brasil \\ Bruno Modesto Silvestre \\ Universidade Estadual de Campinas, Campinas, São Paulo, Brasil \\ Sílvia Cristina Franco Amaral \\ Universidade Estadual de Campinas, Campinas, São Paulo, Brasil
}

\begin{abstract}
Resumo
Esta pesquisa teve por objetivo investigar qual a perspectiva dos agentes pedagógicos sobre as práticas de lazer de adolescentes em cumprimento de medida socioeducativa na cidade de Campinas - SP. Para tal, baseou-se na análise de documentos relacionados ao Sistema Nacional de Atendimento Socioeducativo e na realização de entrevistas semiestruturadas com agentes pedagógicos envolvidos nesse âmbito. Os dados foram relacionados entre si com a finalidade de se apreender como a legislação e o campo prático interagem e se influenciam. Foi possível identificar a existência de práticas de lazer no contexto das medidas socioeducativas e concepções de lazer voltadas à prática da liberdade. Todavia averiguou-se que essas práticas são permeadas por concepções funcionalistas de lazer.
\end{abstract}

Palavras-chave: Lazer. Juventude. Medida Socioeducativa.

\section{YOUTH AND SOCIO-EDUCATIONAL MEASURE: THE LOOK AT PEDAGOGI- CAL AGENTS ON LEISURE PRACTICES}

\begin{abstract}
The aim of this research is investigate the perspective of the pedagogical agents about the leisure practices of adolescents in compliance with socio-educational measure in the city of Campinas - SP. To this end, the research was based on the analysis of documents related to the National Socio-Educational Assistance System and on semi-structured interviews with pedagogical agents involved in this field. The data were related to each other in order to understand how legislation and the practical field interact and influence each other. It was possible to identify the existence of leisure practices in the context of socio-educational measures, and leisure conceptions aimed at the practice of freedom. However, it has been found that these practices are permeated by functionalist conceptions of leisure.
\end{abstract}

Keywords: Leisure. Adolescent. socio-educational measure. 


\title{
JUVENTUDES Y MEDIDA SOCIOEDUCATIVA: LA PERCEPCIÓN DE LOS AGENTES PEDAGÓGICOS SOBRE LAS PRÁCTICAS DE OCIO
}

\begin{abstract}
Resumen
Esta investigación tuvo el objetivo de investigar cuál es la perspectiva de los agentes pedagógicos sobre las prácticas de ocio de adolescentes en cumplimiento de medida socioeducativa en la ciudad de Campinas - SP. Para eso, se basó en el análisis de documentos relacionados al Sistema Nacional de Atención Socioeducativa y en la realización de entrevistas semiestructuradas con agentes pedagógicos participantes en ese ámbito. Los datos se relacionaron entre sí con el fin de percibir cómo la legislación y el campo práctico interactúan y se influencian. Fue posible identificar la existencia de prácticas de ocio en el contexto de medidas socioeducativas y concepciones de ocio relacionadas a la práctica de la libertad. Sin embargo, se averiguó que estas prácticas están impregnadas por concepciones funcionalistas de ocio.
\end{abstract}

Palabras clave: Ocio. Adolescente. Medidas Socioeducativas.

\section{Introdução}

A presente pesquisa ${ }^{1}$ teve por objetivo investigar qual a perspectiva dos agentes pedagógicos, atuantes no sistema socioeducativo, sobre as práticas de lazer de adolescentes em cumprimento de medidas de liberdade assistida, semiliberdade e internação na cidade de Campinas - SP.

Atualmente, a legislação brasileira determina que as autoridades competentes, ao se verificar ato infracional, devem aplicar aos adolescentes infratores as medidas socioeducativas, tais como: advertência, obrigação de reparar o dano, prestação de serviços à comunidade, liberdade assistida, semiliberdade e internação (BRASIL, 1990).

O Sistema Nacional de Atendimento Socioeducativo (SINASE) define que as medidas socioeducativas são responsabilizadoras, de natureza sancionatória e conteúdo socioeducativo, aplicadas somente a adolescentes sentenciados em razão do cometimento de ato infracional (BRASIL, 2006). Nessa perspectiva, as medidas socioeducativas, para Veronese e Lima (2009), têm finalidades especificamente pedagógicas e devem considerar a vulnerabilidade da população à qual se destinam.

O tema se faz relevante devido ao recorrente debate social, legislativo e jurídico que ocorre em âmbito nacional em relação à redução da maioridade penal, a qual é delineada pela Proposta de Emenda à Constituição (PEC) no 171/1993 (BRASIL, 1993) e voltou a chamar a atenção da sociedade no ano de 2015, com a aprovação da mesma na Câmara de Deputados e com consequente envio ao Senado Federal. A PEC em questão traz como principal ponto a redução, em alguns casos, da maioridade penal de 18 para 16 anos.

Entende-se que a proposta de redução da maioridade penal, nos termos apresentados, contraria o processo legal definido pelo Estatuto da Criança e do Adolescente (ECA) (BRASIL, 1990) e pelo SINASE (BRASIL, 2006) para a reinserção social de adolescentes em conflito com a lei. Nota-se, assim, a necessidade de estudos e propostas alternativas a essa medida quanto ao combate à violência, uma vez que dos 21 milhões de adolescentes brasileiros, apenas $0,01 \%$ cometeram atos contra a vida, enquanto que o Brasil é o segundo país no mundo em número absoluto de homicídios de adolescentes, sendo que atualmente os homicídios já representam 36,5\% das causas de morte de adolescentes no País, enquanto para a população total correspondem a 4,8\% (UNICEF, 2015).

\footnotetext{
${ }^{1} \mathrm{O}$ presente trabalho não contou com apoio financeiro de nenhuma natureza para sua realização.
} 
Tendo em vista a importância de ações pedagógicas que auxiliem no combate à violência, é possível pensar sobre como o lazer se configura no âmbito da integração ou reintegração social de adolescentes em conflito com a lei. Desse modo, vale delimitar qual o conceito de lazer que permeia a presente pesquisa. Para tal, concorda-se com a conceitualização de Mascarenhas (2000, p. 17):

[...] o lazer se constitui como um fenômeno tipicamente moderno, resultante das tensões entre capital e trabalho, que se materializa como um tempo e espaço de vivências lúdicas, lugar de organização da cultura, perpassado por relações de hegemonia. Desta forma, dentro de uma perspectiva crítica e de emancipação dos grupos populares, o lazer pode ser entendido também como tempo e espaço para o exercício da cidadania e prática da liberdade.

Dado tal entendimento, é patente afirmar que a concepção de lazer dos agentes pedagógicos que atuam em medidas socioeducativas de liberdade assistida, semiliberdade e internação é de fundamental importância para que esse fenômeno possa ser praticado e vivenciado de maneira plena pelos socioeducandos. Fato ainda mais central quando se levam em conta os aspectos educativos do lazer ${ }^{2}$.

Posto esses elementos, para que se possa discorrer sobre o objetivo levantado, este artigo está organizado, após a apresentação do percurso metodológico, em duas seções: a primeira busca delimitar o conceito de juventude e o contexto das medidas socioeducativas no Brasil; a segunda está organizada de modo a apresentar, a partir dos dados levantados na pesquisa, a concepção de lazer que permeia o trabalho dos agentes pedagógicos envolvidos no âmbito das medidas socioeducativas.

\section{Percurso metodológico}

A pesquisa foi conduzida por meio de uma abordagem qualitativa ${ }^{3}$ de caráter exploratório que, ao buscar identificar as perspectivas de agentes pedagógicos envolvidos na condução do processo de ressocialização de adolescentes no âmbito das medidas socioeducativas, se baseou em análises de documentos pertinentes à temática e na realização de entrevistas semiestruturadas com os agentes pedagógicos em questão.

No que tange à análise documental, foram selecionados e analisados legislações, relatórios, artigos, textos e reportagens, relacionados ao ECA, SINASE, medidas socioeducativas e Fundação CASA. Esses elementos foram relacionados entre si e contribuíram para a composição de um texto-base da pesquisa e para a elaboração das entrevistas.

As entrevistas semiestruturadas ${ }^{4}$ foram realizadas com agentes pedagógicos envolvidos com medidas socioeducativas, no âmbito do processo de reinserção social, que atuam ou atuaram com o regime de internação, semiliberdade ou liberdade assistida. Vale ressaltar que, na cidade de Campinas - SP, as medidas de internação e semiliberdade ficam a cargo do Governo do Estado de São Paulo, por meio da Fundação CASA, enquanto que a liberdade assistida é municipalizada e delegada à organizações não-governamentais (ONGs), cofinanciadas

\footnotetext{
${ }^{2}$ Entre os autores que discutem a relação entre lazer e educação, vale destacar a seguinte formulação de Marcellino (1990, p. 58), na qual o autor aponta o duplo aspecto educativo do lazer: "o primeiro que o lazer é um veículo privilegiado de educação; e a segunda, que para a prática positiva das atividades de lazer é necessário o aprendizado, o estímulo, a iniciação, que possibilitem a passagem de níveis menos elaborados, simples, para níveis mais elaborados, complexos, com o enriquecimento do espírito crítico, na prática ou na observação".

${ }^{3}$ A escolha da pesquisa qualitativa se justifica, segundo Minayo (2011), por privilegiar a dimensão processual do conhecimento.

${ }^{4}$ Esse instrumento de pesquisa, segundo Negrine (2010), é pensado para obter informações de questões concretas, definidas previamente pelo pesquisador. Ao mesmo tempo, possibilita a realização de enfoques não previstos, permitindo que o entrevistado aborde questões relevantes e pertinentes ao tema que originou a entrevista.
} 
pelo poder público (PLANO DECENAL, 2014). Embora tais medidas sejam incumbidas a diferentes setores governamentais, optou-se por abordar as perspectivas de agentes diversos em função do fato de que todos esses contextos têm diretrizes delineadas por uma mesma legislação, o SINASE (BRASIL, 2006).

As entrevistas ocorreram em locais escolhidos pelos participantes, em junho de 2017. Com o intuito de garantir o anonimato dos participantes, os nomes foram substituídos pelo número da entrevista; de todo modo, o perfil de cada entrevistado pode ser conferido no quadro abaixo.

Quadro 1 - Características gerais dos entrevistados

\begin{tabular}{|l|l|l|l|}
\hline $\begin{array}{l}\text { Identidade } \\
\text { de Gênero }\end{array}$ & $\begin{array}{l}\text { Área de Forma- } \\
\text { ção }\end{array}$ & $\begin{array}{l}\text { Medida Socioeducativa } \\
\text { em que atua ou atuou }\end{array}$ & $\begin{array}{l}\text { Tempo de contato } \\
\text { com as medidas so- } \\
\text { cioeducativas }\end{array}$ \\
\hline Feminino & Educação Física & Internação & 7 anos \\
\hline Masculino & Educação Física & Internação & 7 anos \\
\hline Feminino & Serviço Social & Liberdade Assistida & 5 anos \\
\hline Feminino & Serviço Social & $\begin{array}{l}\text { Internação / Liberdade } \\
\text { Assistida / Semiliberdade }\end{array}$ & Não especificou \\
\hline Feminino & Letras & Internação & 2 anos \\
\hline Masculino & Psicologia & Liberdade Assistida & 3 anos \\
\hline
\end{tabular}

Fonte: Dados da pesquisa, 2017.

Também vale frisar que a realização desta pesquisa recebeu aprovação do Comitê de Ética e Pesquisa e que as entrevistas semiestruturadas foram realizadas mediante apresentação do Termo de Consentimento Livre e Esclarecido (TCLE) e aceite do mesmo por parte dos entrevistados ${ }^{5}$.

\section{O contexto das medidas socioeducativas para as juventudes no Brasil}

Ao se buscar apreender a perspectiva de lazer de agentes pedagógicos envolvidos com o processo de reinserção social de adolescentes em conflito com a lei, é de fundamental importância delimitar a compreensão de "juventudes" que permeia este estudo, assim como o processo que culmina no atual contexto das medidas socioeducativas no cenário nacional.

Para fins de políticas sociais, no Brasil, são considerados jovens os indivíduos inseridos na faixa etária entre 15 e 29 anos (ABRAMOVAY; CASTRO, 2015). Todavia, mais do que uma fase da vida, a juventude pode ser considerada uma construção social, cujas características são dependentes da cultura na qual está inserida.

A juventude por definição é uma construção social, uma produção de uma determinada sociedade, relacionada com formas de ver os jovens, inclusive por estereótipos,

\footnotetext{
${ }^{5}$ O número de aprovação de CEP, para garantir a avaliação por pares cegos, será colocado nesta nota de rodapé caso o artigo seja aceito para publicação. Número de aprovação de CEP: 2.100.487. CAAE: 66859017.8 .0000 .5404 .
} 
momentos históricos, referências diversificadas e situações de classe, gênero, raça, grupo, contexto histórico entre outras. Ressalta-se que o emprego do termo juventudes no plural, antes de patrocinar uma perspectiva fracionada, na qual aparecem modelos de jovens separados, sinaliza a existência de elementos comuns ao conjunto dos jovens. (ABRAMOVAY; CASTRO, 2015, p. 14).

Assim, entende-se que a juventude é a fase da vida em que as experiências e situações cotidianas têm grande influência sobre a formação integral do indivíduo. Ademais, o termo "juventudes" caracteriza um estrato social com certas características: "uma realidade palpável que tem sexo, idade, raça, fases, uma época que passa cuja duração não é para sempre, [...] que depende, fundamentalmente, de suas condições materiais e sociais, de seus contextos, de suas linguagens e formas de expressão" (ABRAMOVAY; CASTRO, 2015, p. 14).

Também é possível entender que as representações sobre a juventudes são perpassadas por disputas políticas e assumem diferentes facetas para cada classe social. Nesse cenário, a questão da redução da maioridade penal foi colocada em voga nos últimos anos. Em torno desse ponto, fica evidente que parcela da sociedade brasileira associa ao sistema socioeducativo a mesma lógica punitiva que permeia o sistema carcerário e penal, embora, teoricamente, a única relação entre o Direito da Criança e do Adolescente e o Direito Penal é o fato de que para se configurar um ato infracional é necessária a presença de indícios suficientes da autoria dos fatos, sendo que o direito penal aponta apenas os tipos penais que são considerados crimes ou contravenções, pois a forma de responsabilização pela prática do ato infracional é exclusiva das normativas previstas no ECA (VERONESE; LIMA, 2009).

Até a década de 1920 não havia lei específica que regularizasse a situação de crianças e adolescentes - o Código Penal de 1890 definia que crianças a partir de nove anos de idade poderiam ser levadas a julgamento tal como adultos e submetidas às mesmas medidas punitivas. Em 1927, foi criado o Código de Menores, que estabeleceu como penalmente inimputáveis os jovens de até 17 anos e definiu as ações a serem aplicadas sobre crianças e adolescentes em caso de conflito com a lei. Tal legislação foi reformulada em 1979 e, embora algumas mudanças tenham sido elaboradas, a idade mínima para julgamento permaneceu inalterada, bem como sua doutrina estruturante - a Doutrina da Situação Irregular (também conhecida como Doutrina Menorista), a qual se caracteriza pela forte criminalização da infância em situação de pobreza (QUEIROZ, 2013).

À época do Código de Menores, era comum utilizar o termo "menor" para se referir às crianças e adolescentes envolvidos com ato infracional ou em situação de vulnerabilidade social. Atualmente, são diversas as formas usadas para se referir à população (autor de ato infracional, adolescente em conflito com a lei, adolescentes envolvidos com prática ilícita, entre outros), as quais definem a situação do jovem sem defini-lo por seus atos ${ }^{6}$.

O ECA, vigente desde 1990, foi um marco no que se refere à mudança de paradigma no ordenamento jurídico brasileiro. A Doutrina da Proteção Integral, estruturante também da Constituição Federal de 1988, "parte da compreensão de que as normas que cuidam de crianças e de adolescentes devem concebê-los como cidadãos plenos, porém sujeitos à proteção prioritária, tendo em vista que são pessoas em desenvolvimento físico, psicológico e moral" (SANCHEZ; MINAYO, 2006, p. 15) e agentes de suas próprias trajetórias, capazes de expressar ideias e opiniões (QUEIROZ, 2013). Estabelecido pela Lei no 8.069, o ECA afirma em seu Artigo $4^{\circ}$ que:

É dever da família, da comunidade, da sociedade em geral e do poder público assegurar, com absoluta prioridade, a efetivação dos direitos referentes à vida, à saúde, à alimentação, à educação, ao esporte, ao lazer, à profissionalização, à cultura, à dig-

\footnotetext{
${ }^{6} \mathrm{Na}$ perspectiva de que pensar o jovem como sujeito de direito envolve, também, utilizar de nomenclaturas que não sejam pejorativas, este texto adota prioritariamente o termo "adolescente em conflito com a lei".
} 
nidade, ao respeito, à liberdade e à convivência familiar e comunitária (BRASIL, 1990).

Todavia, na prática, o Estado e a sociedade não garantem aos adolescentes e jovens o acesso a tais direitos, fomentando um contexto no qual estes se veem na necessidade de recorrer a práticas ilícitas a fim de alcançar condições mínimas de sobrevivência, o que os coloca em conflito com a lei das mais variadas formas. Os valores e padrões difundidos nas sociedades capitalistas relacionam-se intimamente com o cometimento de ato infracional e com o ambiente social em que estes jovens são inseridos enquanto camada popular. Não à toa, grande parte dos adolescentes em medida de internação chegam ao sistema socioeducativo por infrações relacionadas à lógica mercadológica do consumo:

Então, quando a gente está falando de maioridade penal, significa criminalização da pobreza, da baixa escolaridade e da cor, porque esses meninos que estão lá, que antes eram internados mais por roubo, hoje a maioria é por tráfico de drogas. Essa é uma estatística não oficial, mas pelas unidades onde eu tenho passado os diretores tem dito, 70 a $80 \%$ dos meninos está lá por tráfico de drogas, então houve, também, uma "profisssionalização" do tráfico. E por que houve essa "profisssionalização"? Falta de opção? Sedução? O sustento da família? Existem todas essas possibilidades [...]. Essa atração pelo crime é uma constante na vida deles [...], os meninos vitimam? Vitimam. Não vamos "tapar o sol com a peneira", eles vitimam, eles são cruéis, eles matam, eles roubam, mas antes eles são vítimas e isso não dá para ignorar. É um reflexo. Não dá para ignorar, não dá para não atrelar uma coisa à outra, e não dá para não se fazer a pergunta: se esses meninos não tivessem sido negligenciados por anos, será que eles estariam [no ato infracional]? [...]. (Entrevista 5, 2017).

Dado tal contexto, é pertinente compreender quais são os procedimentos que a legislação brasileira estabelece para os casos de cometimento de ato infracional por adolescentes. Inicialmente, "são aplicáveis as medidas de proteção à criança e ao adolescente, as quais têm como objetivo assistir crianças e adolescentes em situações de vulnerabilidade, para que esses possam ter condições favoráveis para um desenvolvimento saudável" (SILVA; RUZZIPEREIRA; PEREIRA, 2013, p. 2). Tais medidas protetivas, de acordo com o artigo 98 do ECA, devem ser aplicadas em casos de: I - por ação ou omissão da sociedade ou do Estado; II - por falta, omissão ou abuso dos pais ou responsável; III - em razão de sua conduta (BRASIL, 1990).

O ECA (BRASIL, 1990) também estabelece, em seu Artigo 101, uma série de medidas a serem aplicadas caso verificado algumas das hipóteses apresentadas acima. Entretanto, tais medidas podem não ser suficientemente efetivas para evitar que o adolescente em conflito com a lei reincida em tal comportamento; nesse caso, passa-se ao cumprimento das medidas socioeducativas. De acordo com o ECA, são seis as medidas socioeducativas aplicáveis a adolescentes julgados pela prática de ato ilícito: advertência, obrigação de reparar o dano, prestação de serviços à comunidade, liberdade assistida, semiliberdade e internação, sendo que tais ações devem sempre envolver o contexto social ao qual pertence o adolescente e visar a sua inclusão social (BRASIL, 1990).

De acordo com o texto do documento do SINASE (BRASIL, 2006, p. 32), "medidas socioeducativas são responsabilizadoras, de natureza sancionatória e conteúdo socioeducativo, aplicadas somente a adolescentes sentenciados em razão do cometimento de ato infracional". Além disso, essas medidas "têm finalidades especificamente pedagógicas e levam em consideração a vulnerabilidade do público a[o] qual se destina[m]" (VERONESE; LIMA, 2009, p. 29).

Em consonância com o estabelecido pelo ECA (BRASIL, 1990), surge em meados da última década uma política social com fim específico sobre o processo de reinserção social de crianças e jovens em conflito com a lei. Neste sentido, o SINASE (BRASIL, 2006) é um 
subsistema do Sistema de Garantia de Direitos (SGD), configurado como uma política pública cujo intuito é a inclusão dos indivíduos menores de 18 anos autores de atos infracionais, e que visa à interação entre os diferentes campos das políticas públicas, de modo a proporcionar a intersetorialidade no cumprimento de seu propósito. Pode ser definido também como:

[...] conjunto ordenado de princípios, regras e critérios, de caráter jurídico, político, pedagógico, financeiro e administrativo, que envolve desde o processo de apuração de ato infracional até a execução de medida socioeducativa. Esse sistema nacional inclui os sistemas estaduais, distrital e municipais, bem como todas as políticas, planos, e programas específicos de atenção a esse público. (BRASIL, 2006, p. 22)

O SINASE foi criado e organizado em 2006 e instituído pela Lei Federal 12.594/2012, resultante de uma parceria entre a Secretaria Especial dos Direitos Humanos (SEDH) e o Conselho Nacional dos Direitos da Criança e do Adolescente (CONANDA), com apoio do Fundo das Nações Unidas para a Infância (UNICEF), os quais se utilizaram de diretrizes do ECA, principalmente no tocante à natureza pedagógica da medida socioeducativa. Além disso, o SINASE tem como inspiração os acordos internacionais dos quais o Brasil é signatário, especialmente aqueles referentes aos direitos da criança e do adolescente (BRASIL, 2006).

Em linhas gerais, o SINASE (BRASIL, 2006) é um documento que, em complemento ao ECA (BRASIL, 1990), fornece diretrizes à aplicação das medidas socioeducativas em todos os sentidos, desde a "forma política de traçar as diretrizes pedagógicas em cada programa de atendimento" até o quadro de profissionais, parâmetros arquitetônicos das unidades e "previsão orçamentária para execução e manutenção das medidas socioeducativas" (VERONESE; LIMA, 2009, p. 39).

Desse modo, é neste cenário que se organiza o trabalho e se inserem, conforme colocado pelo ECA, os agentes públicos executores de medidas socioeducativas, ou, como referese esta pesquisa, os agentes pedagógicos que atuam no âmbito das mesmas.

\section{O olhar dos agentes pedagógicos sobre o lazer de adolescentes em medidas socioeducati- vas}

Para se apreender as concepções de lazer dos agentes pedagógicos que atuam no âmbito das medidas socioeducativas, além da análise das entrevistas semiestruturadas, levaramse em conta o lazer enquanto um direito social, o contexto no qual essas medidas foram delineadas e o histórico legal da reinserção social no Brasil.

Vale destacar que aqui se entende toda a atuação dos agentes em questão como eminentemente educacional. Nesse sentido, Mészáros (2014) defende que a educação deve ser permanente, ou não é educação, e que as práticas educacionais devem permitir aos educadores e aos educandos trabalharem concepções que almejem as mudanças necessárias para a construção de um modelo de sociedade que supere a atual lógica de organização societal de exploração do trabalho e das demais relações humanas.

As práticas e vivências de lazer ocorrem em um espaço e tempo determinados que, em grande medida, são utilizados para caracterizar esse fenômeno. Não é por menos que a parcela de tempo em que o lazer ocorre é objeto de intensos debates no campo teórico no qual ele se insere. Acerca dessa discussão, no Brasil, diversos foram os conceitos de tempo utilizados na tentativa de descrever a parcela de tempo no qual o lazer ocorre: tempo livre, tempo disponível, tempo conquistado, tempo livre de trabalho, tempo de não trabalho, entre outros (GOMES, 2004). Mais do que uma discussão semântica, essas diversas expressões carregam consigo concepções de mundo, de sociabilidade humana, assim como de lazer. 
Nesse sentido, a concepção de tempo que permeia este artigo é a de tempo livre, não a que carrega a noção de que é possível ser realmente livre sob a lógica do metabolismo social do capital, mas sim a perspectiva de que o lazer, assim como outras manifestações da cultura que se situam nesse tempo, materializa-se enquanto um espaço para o exercício de ser livre (MASCARENHAS, 2000). Essa distinção se faz ainda mais importante ao se levar em conta o contexto das medidas socioeducativas, afinal a semiliberdade e internação se caracterizam pela privação do espaço e tempo de vida dos adolescentes em conflito com a lei.

O lazer, para além das definições abordadas, também é denominado pelo artigo $6^{\circ}$ da Constituição de 1988 (BRASIL, 1988) como um direito social - bem como a educação, a saúde, a alimentação, o trabalho, a moradia, o transporte, a segurança, a previdência social, a proteção à maternidade e à infância, e a assistência aos desamparados. Dessa forma, também figura em legislações infraconstitucionais, como no ECA (BRASIL, 1900). Todavia, o lazer figura entre os direitos que recebem menor orçamento e atenção estatal. De acordo com Santos e Amaral (2010), essa situação está relacionada à ausência de definição política do tema, já que:

[...] uma definição política indica-nos os modos de dar materialidade a uma concepção teórica de lazer, e está a ela intrinsecamente ligada; determina qual, ou quais, as instituições estatais responsáveis pela política, qual sua fonte de financiamento, quais suas diretrizes, mecanismos, princípios e objetivos. (2010, p. 4).

Apesar da menor atenção do Estado em relação ao tema, o lazer quando entendido, conforme Mascarenhas (2000), como um espaço para o exercício da cidadania e prática da liberdade, alia-se à ideia de uma educação que possibilite ao indivíduo o desenvolvimento da autonomia, sendo este um objetivo também das medidas socioeducativas. Nesse sentido, surge a importância de alternativas pedagógicas que contribuam no processo de reinserção social. Olhando para as diferentes perspectivas da ação pedagógica dos agentes entrevistados nesta pesquisa, é possível identificar os diversos temas ligados a essa ação, dentre eles, destacam-se os relacionados ao lazer.

No tocante à concepção de lazer dos agentes pedagógicos, a principal aferição diz respeito ao fato de que o lazer é considerado por todos como uma prática educativa e, como tal, deve ser uma atividade que faça parte, de maneira integral, das instituições responsáveis pelas medidas socioeducativas.

[...] eu penso que o lazer não pode ser encarado como um momento em que não há processo educativo; eu acho que lazer não é estar ocioso, né, do tipo "estou na rede, descansando". Eu acho que o lazer não pode ser encarado desta forma. Eu acho que é um não trabalho, mas é um não trabalho no âmbito profissional, mas ele é produtivo, ele é educativo. Eu acho que é nesse sentido, não tenho muitas questões acadêmicas para conceituar lazer para você, mas acho que não pode ser um tempo desperdiçado; se eu quero ter ócio, é outra vida... "ah, hoje eu quero ficar 'mofando' o dia inteiro", acho que todo mundo tem direito a ter, mas acho que o lazer precisa ser um espaço que seja divertido, precisa ser um espaço onde haja processo educativo envolvido, né, que esteja acontecendo de forma prazerosa também, além de divertido. Eu acho que é isso. (Entrevista 1, 2017).

Em seus relatos, os entrevistados descrevem o que entendem por práticas de lazer nas Instituições às quais tiveram acesso, descrevendo-as como atividades lúdicas e/ou esportivas.

Mas, assim, no período de férias, é o período em que o lazer é mais produtivo dentro do espaço [...], há um investimento muito grande em, por exemplo, gincanas, coisas desse tipo, para tornar aquele momento das férias mais prazeroso, né. (Entrevista 1, 2017). 
As práticas de lazer costumam ser associadas às aulas de Educação Física, principalmente ao futebol:

Se existe? Muito [...], eles têm as práticas corporais de atividades físicas com um professor de Educação Física que cada unidade tem, que faz até um horário diferenciado para poder proporcionar a esses meninos atividades de lazer. [...] Às vezes, aos finais de semana, por exemplo, mesmo sem o professor, os agentes de apoio socioeducativo sobem com os meninos e deixam eles lá, fazendo o que eles quiserem, jogando o que eles quiserem - quase sempre, o futebol. [...] (Entrevista 5, 2017).

Talvez as práticas corporais de lazer, talvez quando ele estivesse no final de semana, quando não tem o expediente pedagógico, e aí... a parte da segurança que dá uma bola para eles jogarem futebol na quadra, ou a mesa de tênis de mesa para eles praticarem lá, livremente [...] (Entrevista 2, 2017).

Pelo fato de ser um direito social, também garantido pelo ECA (BRASIL, 1990), e ter o seu aspecto educativo, a primeira aferição, basilar para o olhar sobre a concepção de lazer dos agentes pedagógicos que atuam em medidas socioeducativas, é que o lazer figura como uma prática e vivência de adolescentes em conflito com a lei que se encontram sob medidas de semiliberdade e internação ${ }^{7}$, ou seja, o lazer é parte constituinte da ação dos agentes educativos.

Por outro lado, quando se trata da medida de liberdade assistida, foi possível apreender a inexistência de práticas de lazer, ou mesmo a ausência de preocupação das instituições com tal dimensão, como é possível averiguar no trecho da entrevista abaixo.

[...] a gente não promove. [...]. Falando pela experiência da liberdade assistida, que é uma experiência dessa instituição, eu não vejo isso como uma preocupação, de fato. Por mais que esteja lá no ECA, que tem direito ao lazer, e tudo mais, eu acho que essa não é uma preocupação, eu acho que a nossa preocupação - nossa, que eu digo, é dessa nossa política e da sociedade em geral - é exatamente o contrário do lazer, é inserir no mercado de trabalho, é fazer massa trabalhadora, é qualificar profissionalmente de alguma forma para exercer tal função, e eu acho que pouco se discute sobre lazer, talvez porque se tenha uma imagem ou visão de que são todos vagabundos, então "que lazer que você quer falar para vagabundo?". (Entrevista 6, 2017).

Apesar dessa característica, optou-se por manter a perspectiva de lazer de agentes que atuam na medida de liberdade assistida, tanto pela argumentação exposta na metodologia, como pelo fato de eles expressarem concepções de lazer que permitiram um maior entendimento sobre a questão.

É possível identificar que as percepções dos agentes dialogam, em grande medida, com as chamadas concepções funcionalistas do lazer. Compreendem-se tais concepções conforme a seguinte definição de Padilha (1992, p. 3): "entende-se por funcionalista toda aquela abordagem que concebe o lazer como momento de recuperação ou compensação do que se 'perde' no trabalho".

Apesar de os adolescentes em medidas socioeducativas, a rigor, não exercerem uma atividade laborativa, as concepções que permeiam as instituições em questão apontam claramente para uma lógica de inserção social via o oferecimento do aprendizado de determinados ofícios, uma vez que focam suas ações de ressocialização na inserção dos jovens no mercado de trabalho, principalmente na medida de liberdade assistida.

\footnotetext{
${ }^{7}$ Estudos como os de Carneiro et al. (2016) e Conceição (2013) apontam para a existência do lazer entre os adolescentes que cumprem medidas socioeducativas, realizando análises dessas práticas.
} 
Desse modo, ainda vale destacar, como aponta Marcellino (1990), que as abordagens funcionalistas do lazer - classificadas como romântica, moralista, compensatória ou utilitarista - são a expressão de posições conservadoras que buscam a manutenção de ordem e instrumentalizam o lazer à disciplina, obrigações da vida social, atividades socialmente aceitas e moralmente corretas.

Nesse cenário, é interessante notar que, a despeito de concepções funcionalistas, os agentes pedagógicos demonstram compreensões de lazer que dialogam com perspectivas críticas do lazer, vide o trecho da entrevista abaixo:

Eu vejo enquanto lazer é o você poder estar em um espaço, um ambiente, ou praticar alguma coisa que te dá sentido para a vida; então, eu vejo o lazer como... você estar em um ambiente, com pessoas ou sozinho, mas que àquele espaço você se sinta pertencente, né? (Entrevista 4, 2017)

Essa questão demonstra que as ações dos agentes pedagógicos não estão totalmente dominadas pela lógica funcionalista, mas apresentam contradições, nas quais as resistências, as acomodações, as submissões e os conflitos entre instituições, legislações, classes e grupos sociais se evidenciam e se materializam em um tempo e espaço de lazer com fissuras, mas que possibilitam uma prática voltada ao exercício de ser livre.

Com isso, pode-se afirmar que, embora as instituições responsáveis pelas medidas socioeducativas estejam organizadas de modo a privilegiar as concepções funcionalistas de lazer, o ponto de vista dos agentes pedagógicos está permeado pela noção de prática da liberdade.

As propostas de lazer sob uma ótica não funcionalista são relevantes na medida em que possibilitam ao adolescente em conflito com a lei o desenvolvimento de uma nova forma de ver o mundo, percebendo-se enquanto indivíduo dentro da sociedade, incumbido de direitos, deveres e papel sociopolítico. Assim, o lazer desenvolvido com o intuito educativo pode contribuir significativamente com a formação do senso crítico, podendo ser uma ferramenta no processo de (res)socialização, em conjunto com outras estratégias pedagógicas.

Desse modo, a presença do lazer, por meio da ação dos agentes pedagógicos, além de ter sua característica educativa, também colabora para que as instituições de atendimento socioeducativo se afastem da lógica punitivista que permeia o sistema carcerário brasileiro, uma vez que os adolescentes em conflito com a lei, ao exercerem seu direito ao lazer, aproximamse mais do que entendemos como cidadania e do que se espera que um indivíduo em situação regular tenha acesso em sua vida cotidiana.

\section{Considerações finais}

Este trabalho teve por objetivo investigar qual a perspectiva de agentes pedagógicos sobre as práticas de lazer de adolescentes em cumprimento de medidas socioeducativas. Dentro disso, foi possível constatar que a lógica imposta pelas Instituições de Atendimento Socioeducativo é fortemente influenciada pela perspectiva funcionalista, no sentido de que o lazer deva ser forma de alívio das tensões provenientes da internação e corroborar a formação para o trabalho. Entretanto, o lazer na perspectiva dos agentes pedagógicos entrevistados é associado à educação e à prática da liberdade, no sentido de que pode ser um instrumento para o desenvolvimento de autonomia e da cidadania.

Esse panorama demonstra a necessidade de se compreender o lazer como instrumento e objeto da educação, de forma que as instituições passem a compreendê-lo como mais do que uma compensação frente às pressões sociais e referentes às próprias medidas socioeducativas.

Considera-se que a proposição e efetivação do lazer enquanto direito social no contexto das medidas socioeducativas configuram-se como uma forma de afastar as instituições da 
lógica punitivista. Não obstante, é de fundamental importância que o Estado e a sociedade como um todo passem a compreender os adolescentes em conflito com a lei enquanto sujeitos, com direitos e obrigações próprios de sua condição peculiar de pessoa em desenvolvimento.

\section{Referências}

ABRAMOVAY, M.; CASTRO, M. G. Ser jovem no Brasil hoje: políticas e perfis da juventude brasileira. In: Humberto Dantas. (Org.). Caderno Adenauer XVI - Juventude Brasil. 1. ed. Rio de Janeiro: Fundação Konrad Adenauer, 2015. v. 1, p. 13-25. Disponível em <http://www.kas.de/wf/doc/16496-1442-5-30.pdf>. Acesso em: 10 dez.2017.

BRASIL. Sistema Nacional de Atendimento Socioeducativo - SINASE. Secretaria Especial dos Direitos Humanos. Brasília: CONANDA, 2006. Disponível em: <http://www.conselhodacrianca.al.gov.br/sala-de-imprensa/publicacoes/sinase.pdf $>$. Acesso em: 10 dez. 2017.

Proposta de Emenda à Constituição no 171 de 1993. Diário do Congresso Nacional. Poder Legislativo, Brasília, 27 out. 1993. Seção 1, p. 23062. Disponível em: <http://imagem.camara.gov.br/Imagem/d/pdf/DCD27OUT1993.pdf\#page=10>. Acesso em: 13 dez. 2018.

BRASIL. Lei n. 8.069, de 13 de julho de 1990. Dispõe sobre o Estatuto da Criança e do Adolescente e dá outras providências. Casa Civil - Subchefia para Assuntos Jurídicos. Brasília, 13 jul. 1990. Disponível em: 〈http://www.planalto.gov.br/ccivil_03/leis/18069.htm>. Acesso em: 10 dez. 2017.

Constituição da República Federativa do Brasil, 1988. Brasília: Senado Federal, Centro Gráfico, 1988. 292 p.

CONCEIÇÃO, W. L. Lazer e adolescentes em privação de liberdade: um diálogo possível? Educar em Revista, Curitiba, n. 48, p. 346-346, abr./jun. 2013. Disponível em: <http://www.scielo.br/scielo.php?script=sci_arttext\&pid=S0104-40602013000200022>. Acesso em: 10 dez. 2017.

GOMES, C. L. Lazer - Concepções. In: GOMES, Christianne Luce. Dicionário crítico do lazer. Belo Horizonte: Autêntica, 2004. p. 119-126.

CARNEIRO, K. T. et al. Sobre lazer e possibilidades formativas em adolescentes que cumprem medidas socioeducativas. Pensar a Prática, Goiânia, v. 19, n. 4, p. 867-880, out./dez. 2016.

MARCELLINO, N. C. Lazer e Educação. 2. ed. Campinas: Papirus, 1990.

MASCARENHAS, F. Lazer e grupos sociais: concepções e método. 2000. 142 f. Dissertação (Mestrado em Educação Física) - Programa de Pós-Graduação em Educação Física. Faculdade de Educação Física. Universidade Estadual de Campinas, Campinas, 2000.

MÉSZÁROS, István. Educação para além do capital. 2. ed. São Paulo: Boitempo, 2014. 
MINAYO, M. C. S. Pesquisa social: teoria método e criatividade. Petrópolis: Vozes, 2011.

NEGRINE, A. Instrumentos de coleta de informações na pesquisa qualitativa. In: MOLINA NETO, V; TRIVIÑOS, A. N. S. A pesquisa qualitativa em Educação Física. Porto Alegre: UFRGS/SULINA, 2010. p. 61-93.

PADILHA, V. Trabalho e lazer: reflexões sobre a abordagem funcionalista. (Monografia). 1992. 60 p. Especialização em Lazer. Universidade Estadual de Campinas, Campinas, 1992.

PLANO DECENAL. Plano Municipal de Atendimento Socioeducativo (2014-2024), Secretaria Municipal de Cidadania, Assistência e Inclusão Social / Conselho Municipal de Direito da Criança e Adolescente. Campinas, 2014. Disponível em <https://cmdca.campinas.sp.gov.br/cmdca/planos>. Acesso em: 25 abr. 2018.

QUEIROZ, P. E. C. Da doutrina "menorista" à proteção integral: mudança de paradigma e desafios na sua implementação. Conteúdo Jurídico, Brasília/DF: 01 abr. 2013. Disponível em: <http://www.conteudojuridico.com.br/?artigos\&ver=2.42716\&seo=1>. Acesso em: 10 dez. 2017.

SANCHEZ, R. N.; MINAYO, M. C. S. Violência contra crianças e adolescentes: questão histórica, social e de saúde. In: Ministério da Saúde (Org.). Violência faz mal à saúde. Brasília: Ministério da Saúde, 2006.

SANTOS, F. C.; AMARAL, S. C. F. Sobre lazer e políticas sociais: questões teóricoconceituais. Pensar a Prática, [S.1.], v. 13, n. 3, dez. 2010. Disponível em: <https://www.revistas.ufg.br/fef/article/view/10175>. Acesso em 13 dez. 2017.

SILVA, D. C. D. O.; RUZZI-PEREIRA, A.; PEREIRA, P. E. Fatores protetivos à reincidência ao ato infracional - concepções de adolescentes em privação de liberdade. Cadernos de Terapia Ocupacional da UFSCar, São Carlos, v. 21, n. 3, p. 553-561, 2013. Disponível em: <http://www.cadernosdeterapiaocupacional.ufscar.br/index.php/cadernos/article/view/915>.

Acesso em: 10 dez. 2017.

UNICEF. UNICEF é contra a redução da maioridade penal. UNICEF, Brasília, 18 mar. 2015. Disponível em <https://www.unicef.org/brazil/pt/media_29163.htm>. Acesso em: $10 \mathrm{dez}$. 2017.

VERONESE, J. R.; LIMA, F. S. O Sistema Nacional de Atendimento Socioeducativo (SINASE): breves considerações. Revista Brasileira de Adolescência e Conflitualidade, [S.1.], v. 1 n. $1, \quad$ p. 29-46, $2009 . \quad$ Disponível em: <http://pgsskroton.com.br/seer/index.php/adolescencia/article/view/185>. Acesso em: 10 dez. 2017.

Recebido em: 26/12/2017

Revisado em: 10/05/2018

Aprovado em: 10/05/2018

Endereço para correspondência:

dayatrentin@ hotmail.com 
Dayane Ferraz Lacerda Trentin

Universidade Estadual de Campinas, Faculdade de Educação Física.

Departamento de Educação Motora

Cidade Universitária

13083851 - Campinas, SP - Brasil 